\title{
Stratification for Confounding - Part 2: Direct and Indirect Standardization
}

\author{
Giovanni Tripepi $^{\mathrm{a}}$ Kitty J. Jager ${ }^{\mathrm{b}}$ Friedo W. Dekker ${ }^{\mathrm{b}, \mathrm{c}}$ Carmine Zoccali $^{\mathrm{a}}$ \\ ${ }^{a}$ CNR-IBIM, Clinical Epidemiology and Physiopathology of Renal Diseases and Hypertension of Reggio Calabria, \\ Reggio Calabria, Italy; ${ }^{b}$ ERA-EDTA Registry, Department of Medical Informatics, Academic Medical Center, \\ University of Amsterdam, Amsterdam, and ${ }^{\mathrm{C}}$ Department of Clinical Epidemiology, Leiden University \\ Medical Center, Leiden, The Netherlands
}

\section{Key Words}

Confounding $\cdot$ Direct standardization $\cdot$ Indirect

standardization $\cdot$ Stratification

\begin{abstract}
Standardization is a method used to compare observed and expected rates of a given disease/outcome by removing the influence of factors that may confound the comparison. There are two major standardization methods: one is used when the 'standard' is the structure of a population (direct method) and the other when the 'standard' is a set of specific event rates (indirect method). The direct standardization is commonly used for large populations while the indirect one is applied to populations of relatively small dimensions.
\end{abstract}

Copyright $\odot 2010$ S. Karger AG, Basel

\section{Introduction}

In a previous paper of this series, we focused on the Mantel-Haenszel method [1], a statistical technique that allows to calculate an overall, unconfounded effect estimate of a given exposure for a specific disease/outcome by pooling stratum-specific relative risks (RRs) or odds ratios. In this paper, we describe another technique based on stratification [1], termed 'standardization' that is ap- plied to compare observed and expected rates of a given disease/outcome by removing the influence of extraneous factors (confounders) [2]. Standardization is well suited for comparing the rate of a given outcome (for example mortality) in large populations that differ for important prognostic factors like age, gender and social economical status. In such circumstances, due to the presence of confounding factors, a crude comparison of mortality rates between the two populations may be misleading [2]. There are two major standardization methods: one is used when the available 'standard' is the structure of a reference population (direct method) and the other when the 'standard' is a set of specific event rates (indirect method). For example, when controlling for gender in two populations by using direct standardization, the external standard could be set as the gender distribution derived by the combination of the two populations while in the indirect standardization the external standard is a series of gender-specific rates.

\section{Direct Method of Standardization}

Here we consider a hypothetical study investigating the mortality rate in two large populations of moderate drinkers $(n=80,000)$ and nondrinkers $(n=80,000)$. Age is a potential confounder [2] because (1) it is significantly

\section{KARGER}

Fax +41613061234 E-Mail karger@karger.ch www.karger.com
(C) 2010 S. Karger AG, Base

$1660-2110 / 10 / 1164-0322 \$ 26.00 / 0$

Accessible online at:

www.karger.com/nec
Dr. Giovanni Tripepi, MSc

CNR-IBIM, Istituto di Biomedicina, Epidemiologia Clinica e Fisiopatologia

delle Malattie Renali e dell'Ipertensione Arteriosa, c/o Euroline di Ascrizzi Vincenzo

Via Vallone Petrara No. 55/57, IT-89124 Reggio Calabria (Italy)

Tel. +39 0965397 010, Fax +39 0965 26879, E-Mail gtripepi@ibim.cnr.it 
Table 1. Death occurrence in moderate drinkers and nondrinkers according to age strata

\begin{tabular}{|c|c|c|c|c|c|c|}
\hline \multirow[t]{2}{*}{ Age strata } & \multicolumn{3}{|c|}{ Moderate drinkers (exposed) } & \multicolumn{3}{|c|}{ Nondrinkers (unexposed) } \\
\hline & $\begin{array}{l}\text { number of } \\
\text { individuals }\end{array}$ & $\begin{array}{l}\text { number of } \\
\text { deaths }\end{array}$ & $\begin{array}{l}\text { crude mortality rate (for } \\
100,000 \text { individuals) }\end{array}$ & $\begin{array}{l}\text { number of } \\
\text { individuals }\end{array}$ & $\begin{array}{l}\text { number of } \\
\text { deaths }\end{array}$ & $\begin{array}{l}\text { crude mortality rate } \\
\text { (for } 100,000 \text { individuals) }\end{array}$ \\
\hline$<30$ years & 25,000 & 50 & 200 & 30,000 & 60 & 200 \\
\hline $30-60$ years & 30,000 & 300 & 1,000 & 35,000 & 210 & 600 \\
\hline$\geq 60$ years & 25,000 & 500 & 2,000 & 15,000 & 360 & 2,400 \\
\hline Total & 80,000 & 850 & 1,062 & 80,000 & 630 & 787 \\
\hline
\end{tabular}

The crude mortality rate (deaths/100,000 individuals) is calculated in each stratum by the standard formula: (number of deaths/ number of individuals) $\times 100,000\left(\right.$ or $\left.\times 10^{5}\right)$.

Table 2. Observed and expected death rate in the overall population (moderate drinkers + nondrinkers)

\begin{tabular}{|c|c|c|c|c|c|}
\hline $\begin{array}{l}\text { Age } \\
\text { strata }\end{array}$ & $\begin{array}{l}\text { Proportion of } \\
\text { deaths in moderate } \\
\text { drinkers }\end{array}$ & $\begin{array}{l}\text { Proportion } \\
\text { of deaths in } \\
\text { nondrinkers }\end{array}$ & $\begin{array}{l}\text { Total number of individuals } \\
\text { in each age category (moderate } \\
\text { drinkers + nondrinkers) }\end{array}$ & $\begin{array}{l}\text { Age-adjusted number } \\
\text { of deaths in } 160,000 \\
\text { moderate drinkers }\end{array}$ & $\begin{array}{l}\text { Age-adjusted number of deaths in } \\
160,000 \text { nondrinkers }\end{array}$ \\
\hline$<30$ years & 0.002 & 0.002 & $25,000+30,000=55,000$ & $0.002 \times 55,000=110$ & $0.002 \times 55,000=110$ \\
\hline $\begin{array}{l}30-60 \\
\text { years }\end{array}$ & 0.01 & 0.006 & $30,000+35,000=65,000$ & $0.01 \times 65,000=650$ & $0.006 \times 65,000=390$ \\
\hline \multirow[t]{2}{*}{$\geq 60$ years } & 0.02 & 0.024 & $25,000+15,000=40,000$ & $0.02 \times 40,000=800$ & $0.024 \times 40,000=960$ \\
\hline & & & Total $=160,000$ & $\begin{array}{l}\text { Total expected } \\
\text { deaths }=1,560\end{array}$ & $\begin{array}{l}\text { Total expected } \\
\text { deaths }=1,460\end{array}$ \\
\hline
\end{tabular}

Table 3. Adjusted death rate in moderate drinkers and non drinkers weighted for the mean age distribution

\begin{tabular}{ll}
\hline & $\begin{array}{l}\text { Adjusted death rate } \\
\text { (for 100,000 individuals) }\end{array}$ \\
\hline $\begin{array}{l}\text { In moderate drinkers when weighted for the mean age } \\
\text { distribution of moderate drinkers and nondrinkers }\end{array}$ & $1,560 / 160,000=975$ \\
\hline $\begin{array}{l}\text { In nondrinkers when weighted for the mean age } \\
\text { distribution of moderate drinkers and nondrinkers }\end{array}$ & $1,460 / 160,000=912$
\end{tabular}

different in the two populations (the proportion of individuals aged $\geq 60$ years is higher in moderate drinkers than in nondrinkers; table 1), (2) it is related to the outcome of interest (mortality) and because (3) there is no scientific evidence that ageing is in the potential causal pathway mediating the link between alcohol intake and death.

As a first step, the authors stratified the two populations according to age strata and calculated the stratumspecific proportion of deaths, separately in moderate drinkers (exposed) and nondrinkers (unexposed) (table 1).
The crude mortality rate was 1,062 deaths $/ 10^{5}$ in moderate drinkers and 787 deaths $/ 10^{5}$ in nondrinkers. Therefore, the crude RR (that is the ratio of death rates in the exposed and unexposed groups) is $1,062 / 787=1.35$. This implies that the crude mortality rate is $35 \%$ higher in moderate drinkers that in nondrinkers. If moderate drinking is causally implicated in the risk of death, the relationship between moderate alcohol intake and mortality should be independent of age (the potential confounder). To control for the confounding effect of age, the authors used the direct method of standardization. To this end, they calculated the proportion of deaths in each age category, sepa- 
Table 4. Observed and expected death rate in a hypothetical sample of 545 individuals

\begin{tabular}{llllll}
\hline $\begin{array}{l}\text { Age } \\
\text { categories }\end{array}$ & $\begin{array}{l}\text { Observed } \\
\text { death cases }\end{array}$ & $\begin{array}{l}\text { Total number of indivi- } \\
\text { duals in each age category }\end{array}$ & $\begin{array}{l}\text { Observed proportion } \\
\text { of deaths }\end{array}$ & $\begin{array}{l}\text { Standard } \\
\text { death rate }\end{array}$ & $\begin{array}{l}\text { Expected } \\
\text { death cases }\end{array}$ \\
\hline $30-39$ years & 16 & 180 & 0.0889 & 0.0669 & $0.0669 \times 180=12$ \\
$40-49$ years & 22 & 140 & 0.1571 & 0.0948 & $0.0948 \times 140=13$ \\
$50-59$ years & 25 & 135 & 0.1852 & 0.1209 & $0.1209 \times 135=16$ \\
$60-69$ years & 19 & 90 & 0.2111 & 0.1370 & $0.1370 \times 90=12$ \\
\hline Total & 82 & & & & 53 \\
\hline
\end{tabular}

rately in moderate drinkers and nondrinkers (see second and third columns in table 2), and summed up the stratum-specific number of individuals in the overall (combined) populations (see fourth column in table 2).

Then the authors calculated the expected, stratumspecific number of deaths in a hypothetical population of 160,000 moderate drinkers and of 160,000 nondrinkers weighed for the mean age distribution of moderate drinkers and nondrinkers (see fifth and sixth columns). Summing up the stratum-specific expected number of deaths gave 1,560 expected deaths in moderate drinkers and 1,460 expected deaths in nondrinkers. The adjusted death rates are the mortality rates that the two populations would have experienced if they had had the same distribution of the confounding factor (table 3).

By using the age-adjusted death rates, the authors calculated the age-adjusted RR of death (moderate drinking vs. nondrinking) by the standard formula:

adjusted $\mathrm{RR}=$ 975/912 $=1.07$.

After data adjustment by age, the RR of death changed toward the null hypothesis (that is no independent effect of moderate drinking on the risk of death). Furthermore, by comparing age-adjusted $(\mathrm{RR}=1.07)$ and unadjusted RRs ( $R R=1.35$ ) of death, the authors found a difference by more than $20 \%$, a figure indicating a strong confounding effect of age. In this case, age engendered 'positive confounding' because it determined an overestimation of death risk associated with moderate alcohol intake. When using direct standardization for comparing two large populations, the statistical significance of the adjusted effect estimate $(\mathrm{RR}=1.07)$ and the corresponding 95\% confidence interval (CI) is not an issue because due to the large sample size of the two populations also a very modest risk increase $(+7 \%)$ may be significant. The calculation of the $95 \%$ CI of the adjusted RR is important particularly when comparing samples of relatively small dimension (for details, see Chiang [3]).
In the renal field, the direct standardization method was used by Jager et al. [4] investigating whether the relative excess of cardiovascular over noncardiovascular mortality was higher in patients starting dialysis as compared to that in the general population in European countries. For a valid comparison, the higher age and higher percentage of males among dialysis patients had to be taken into account. To this end, age- and sex-specific mortality rates were calculated both for dialysis patients and the general population. Then, a weighted average over strata of age and sex was calculated, with the age and sex distribution of the general population in these European countries as 'standard'. By this approach, the authors found that the cardiovascular/noncardiovascular mortality rates ratio in patients starting dialysis did not differ from that in the general population.

An important limitation of the direct method of standardization is that it is inefficient when the number of categories of the confounding variable is relatively high and the sample size is relatively low. In this instance, it is preferable to use the indirect method of standardization.

\section{Indirect Method of Standardization}

In the indirect method of standardization, instead of using the distribution of the confounding variable (for example age) in a standard population, we use a series of standard age-specific rates. In this way, the expected number of deaths is calculated for each stratum of age in the population of interest. Next, the ratio of observed to expected number of deaths is taken and reported as a standardized mortality rate (SMR). Here we consider a hypothetical study including a random sample of 545 individuals in which the mortality rate was compared to that in the general, reference population (the standard death rate; table 4 ). 
Table 5. Interpretation of SMR values

\begin{tabular}{ll}
\hline Interpretation \\
\hline SMR $>1$ & $\begin{array}{l}\text { The death risk in the population under investigation is } \\
\text { higher than that in the reference population }\end{array}$ \\
\hline $\mathrm{SMR}<1$ & $\begin{array}{l}\text { The death risk in the population under investigation is } \\
\text { lower than that in the reference population }\end{array}$ \\
\hline $\mathrm{SMR}=1$ & $\begin{array}{l}\text { The death risk in the population under investigation is } \\
\text { identical to that in the reference population }\end{array}$ \\
\hline
\end{tabular}

The study population was stratified according to age categories (from 30 to 69 years). In each age stratum, the authors reported the number of observed deaths, the total number of individuals, the observed proportion of deaths as well as the standard, age-specific, death rates derived from available tables of the reference population. The expected number of deaths in all age categories was calculated by multiplying the standard death rates by the number of individuals in each age stratum. By summing up the stratum-specific expected deaths, the authors found 53 total expected deaths that represent the death rate that the population under investigation would have experienced if it had had the same age-specific death rates as the reference population. The SMR is calculated by dividing the total number of observed deaths by the total number of expected deaths:

$$
\mathrm{SMR}=82 / 53=1.55(95 \% \mathrm{CI}=1.23-1.92)
$$

where the $95 \%$ CI of the SMR was calculated by the standard formula (see appendix for mathematical details).

An SMR of 1.55 indicates that the death risk in the population under investigation is $55 \%$ higher than that expected if the population had experienced the same agespecific death rates as the reference population. This SMR of 1.55 is statistically significant because the corresponding 95\% CI (1.23-1.92) does not include 1. This effect estimate is standardized, i.e. adjusted, for the confounding effect of age. In table 5 , all possible interpretations of SMR values are given.

The indirect standardization method was applied in a recent study in Taiwan investigating the SMR for urological cancers in herbalists [5]. The SMR for urological cancers was significantly higher in Chinese herbalists as compared to the general population $(\mathrm{SMR}=3.1,95 \%$ $\mathrm{CI}=1.4-5.9)$, and this was also true for kidney cancer $(\mathrm{SMR}=3.8,95 \% \mathrm{CI}=1.4-8.3)$ and renal failure $(\mathrm{SMR}=$ $2.4,95 \% \mathrm{CI}=1.4-3.8)$. The authors concluded that Chi- nese herbalists had a significantly higher risk for urological cancers as compared to the general population and emphasized the importance of safety assessments of Chinese herbs on a large scale.

\section{Conclusions}

Direct and indirect methods of standardization address confounding when comparing the rate of a given outcome (like mortality) between two populations that differ for important prognostic factors (like age, gender and social-economical status). These two methods are used for both descriptive and analytical purposes. By the direct method of standardization, we calculate adjusted mortality rates and adjusted RRs. The indirect method of standardization allows to calculate the SMR, that is the ratio between the observed number of deaths in a given population and the death rate expected assuming that the population under investigation experienced the same age-specific death rates as the reference population.

\section{Appendix}

95\% CI calculation for SMR:

$$
\text { Lower limit }=\frac{\text { Obs. }\left\{1-\frac{1}{9 \times \text { Obs. }}-\frac{z}{3}\left(\sqrt{\frac{1}{\text { Obs. }}}\right)\right\}^{3}}{\text { Exp. }}
$$

where Obs. $=$ number of observed deaths, Exp. $=$ number of expected deaths and $\mathrm{z}=$ constant (1.96).

\section{References}

1 Tripepi G, Jager KJ, Dekker FW, Zoccali C: Stratification for confounding. 1. The Mantel-Haenszel formula. Nephron Clin Pract 2010, in press.

2 Jager KJ, Zoccali C, Macleod A, Dekker FW: Confounding: what it is and how to deal with it. Kidney Int 2008;73:256-260.

3 Chiang CL: Standard error of the age adjusted death rate. Vital Stat Spec Rep 1961;47:275-285.

4 de Jager DJ, Grootendorst DC, Jager KJ, van Dijk PC, Tomas LMJ, Ansell D, Collart F, Finne P, Heaf JG, De Meester J, Wetzels JFM, Rosendaal FR, Dekker FW: Cardiovascular and non-cardiovascular mortality among patients initiating dialysis. JAMA 2009;302:1782-1789.

5 Yang HY, Wang JD, Lo TC, Chen PC: Increased mortality risk for cancers of the kidney and other urinary organs among Chinese herbalists. J Epidemiol 2009;19:17-23. 